\title{
Is Temporal Summation or Conditioned Pain Modulation Associated with Pain and Functional Outcomes in Patients with Orofacial Pain?
}

\author{
Carla S. Enriquez, PT, DPT, MS, OCS, DAIPM* \\ School of Health Sciences, Stockton University, Galloway, New Jersey, USA. \\ ${ }^{\star}$ Corresponding author: Dr. Carla S. Enriquez, Assistant Professor of Physical Therapy, DPT, School of Health Sciences, Stockton University, Galloway, NJ 08205, USA; \\ Phone: 6096263508; Email: carla.enriquez@stockton.edu
}

Received: February 12, 2019; Accepted: February 20, 2019; Published: February 22, 2019;

\begin{abstract}
Objective: To determine if two psychophysical quantitative sensory tests, temporal summation and conditioned pain modulation are associated with treatment outcomes in patients with orofacial pain.

Methods: During the initial examination of 40 patients with orofacial pain, data were collected on physical function and pain; and measurements of Temporal Summation (TS) and Conditioned Pain Modulation (CPM). At 6-8-weeks follow-up, these pain and function measures were repeated and subjects were asked to rate their perceived level of change.

Results: Insufficient evidence of association between temporal summation and functional outcomes were seen in patients with orofacial pain. However, conditioned pain modulation was associated with subjects' perceived change and least pain reported over one-week periods which reflect symptomatic and functional changes from treatment.
\end{abstract}

Discussion: Results suggest that impairments in CPM affect changes in some measures of pain perception. The implications of CPM as a psychophysical testing paradigm on short term pain outcomes and individual pain experience is a critical piece of consideration in patients who receive treatment for orofacial pain.

Keywords: temporal summation, conditioned pain modulation, pain and disability, orofacial pain

\section{Introduction}

The International Association for the Study of Pain describes orofacial pain as pain perceived in the face and/or oral cavity [1]. In a recent study, investigators estimated the 1-year period prevalence of orofacial pain to be over $16 \%$ of the adult population [2]. Prolonged or intense pain has been shown to trigger neuroplastic changes in the central and peripheral nervous systems in some individuals [3]. The result of these changes includes heightened sensitivity to cutaneous, tactile or noxious stimuli in local or distant body regions, and the sensation of persistent pain in the absence of a triggering stimulus $[4,5]$. These changes in pain perception increase the individuals' likelihood of developing and perpetuating chronic pain [6-9]. Several studies have explored the utility of inducing experimental pain using quantitative sensory tests to identify individuals with altered pain processing mechanisms [10-12].Two methods of indirectly detecting increased sensitivity to pain include Temporal Summation (TS) and Conditioned Pain Modulation (CPM) testing [13]. Both methods have been studied in patients with orofacial pain [10,14,15].

The utility of these tests to identify individuals with abnormal pain responses who might be less likely to respond to standard pain intervention strategies has the potential to provide researchers and clinicians alike with a valuable tool for developing effective treatment strategies that minimize the likelihood of developing chronic pain. A crucial step in this process is to establish the construct validity of these quantitative sensory tests. TS occurs when a series of equally intense noxious neural impulses arrive at a synapse at a frequency such that the duration of these impulses is smaller than the postsynaptic potential, causing a build-up of neurotransmitters released by a single presynaptic neuron. This results in the perception that the intensity of the stimulus increases during the administration of the series of neural impulses, when in fact the intensity remains unchanged. Individuals with altered in pain processing mechanisms experience greater pain from repeated noxious stimuli than what would be expected in neurologically healthy individuals. The response to TS is commonly tested by administering a train of uniform and consecutive noxious stimuli at a constant intensity at the site of pain or at a neutral, painfree site $[16-18,21]$. Prior to testing, the subject is instructed to rate the pain intensity of the first and the last stimulus from a train of 10 stimuli applied at equal intensity and frequency of one stimulation per second. Pain intensity is measured using a Numerical Pain Rating Scale (NPRS). The last pain measurement is subtracted from the first pain measurement, thereby representing the difference between the two measurements of pain perception, given stimuli of equal intensity. A larger difference indicates a greater impairment in pain processing. The noxious stimulus used to test TS is most often mechanical (using 
pin prick or pressure stimulus), thermal (using heat or cold) or ischemic (using a blood pressure cuff). When evaluated using pressure algometry [19], ischemia via cuff compression [20], and heat pulses [18], TS has been shown to demonstrate acceptable reliability. To the author's knowledge, the reliability of TS has not been studied using a pinprick stimulus. Temporal summation has been evaluated in several studies in patients with nonspecific orofacial pain. In relation to pain free controls, TS was enhanced when tested using a pinprick [10] and a heat probe $[11,15]$. There were no differences between groups, however when TS was tested using pressure pain [16]. CPM is a phenomenon whereby the individual perceives less pain when receiving two noxious stimuli administered simultaneously at different body regions, when compared with the perceived intensity of pain associated with the application of one noxious stimuli. This experience is often described as one in which 'pain inhibits pain' $[13,22]$

One of the two stimuli is referred to as the 'test' stimulus, whereas the other, the 'conditioned' stimulus. The test stimulus is administered and measured in a similar manner as with TS testing. Subjects with normal pain processing mechanisms experience a less dramatic increase in pain from TS when the conditioned stimulus is being applied than when the conditioned stimulus is not present. For measurement purposes, the conditioned stimulus measurement is subtracted from the test stimulus, or TS measurement. A smaller difference thereby indicates a greater impairment in pain processing. As is the case with TS testing, test stimuli sites for measuring CPM can be located at the site of pain or at a neutral site, and typically involve mechanical, thermal or ischemic stimuli. Conditioning stimulus sites are located at a neutral site, and are typically produced by thermal or ischemic stimuli. Two different studies addressed the reliability of CPM testing. Both used mechanical pressure as the test stimuli, and ischemic arm pain as the conditioned stimulus $[19,20]$. In one of these studies, the investigators also studied thermal (cold) stimuli as the conditioned stimulus [20]. Reliability was good when using the cold stimuli [20], but conflicting conclusions were drawn regarding ischemic pain. In one study, the investigators reported 'excellent' intra-session reliability, but poor inter-session reliability for the ischemic pain measure, whereas in the other study, the reliability was described as 'acceptable' [19]. To the author's knowledge, the reliability of CPM has not been studied using heat as a conditioned stimulus.

The question of whether measures of CPM are more impaired in patients with orofacial pain has been addressed in the research. In relation to pain free controls, there was no difference between groups when a pinprick test stimulus was paired with a thermal (cold) conditioned stimulus [10]. Conversely, when a pinprick test was paired with pressure as the conditioned stimulus, CPM measures were more impaired in subjects with orofacial pain when tested at the site of pain when compared with pain free controls, but not when tested at a pain free site [14]. These studies addressing TS and CPM in subjects with orofacial pain versus healthy controls suggest that impairments in pain processing can be identified using either of these quantitative tests. The ultimate goal in identifying these subjects with pain processing impairments, once identified, is to determine appropriate interventions for this subpopulation of subjects who are more likely to develop chronic pain. A next step in this process is therefore to determine if greater impairments in TS and CPM are associated with poorer outcomes following treatment. This question has not been addressed to date in patients with orofacial pain. Additionally, no study has addressed the more fundamental questions of whether impairments in TS and/or CPM are correlated with measurements of physical function and pain in patients with orofacial pain when measured concurrently.

Therefore, the aims of this study are twofold:

1. To determine if TS and CPM tests, performed on subjects with orofacial pain, are correlated with physical function and pain measurements during the initial visit for treatment of their orofacial pain, and

2. To determine if TS and CPM tests, performed on subjects with orofacial pain during their initial visit for treatment of their orofacial pain, are associated with changes in physical function and pain at 6 to 8 -weeks follow-up.

\section{Materials and Methods}

This study was a prospective cohort, approved by the Rutgers University Institutional Review Board. Subjects being seen for an initial examination at the Center for Temporomandibular Disorders and Orofacial Pain, Department of Diagnostic Sciences, in the New Jersey School of Dental Medicine, Rutgers University who were between the ages of 18 and 89 were recruited. Subjects were excluded if pregnant, or if any intervention was received during the initial examination visit before all baseline measures could be collected. Written informed consent was obtained from all subjects. This convenience sample was assessed for baseline for measurements of TS and CPM. Baseline data on age, gender, physical function and pain levels were also collected. At between 6 and 8 weeks follow-up, data collection on physical function and pain was repeated, and subjects were asked to rate their perceived change in status. This time frame allowed the author to contact the subject multiple times in the event that initial attempts to contact the subjects failed. All follow-up data were collected via telephone interview. Subjects were tested for pain responses under conditions of TS using \#5.46 von Frey filaments (Stoteling Ltd., USA). A single stimulus (pin prick) and then a train of 10 consecutive stimuli were applied at a frequency of one stimulation per second to the volar forearm of the dominant arm. Subjects were asked to rate the level of pain after the single stimulus was applied, and then at the end of the train of 10 consecutive stimuli using an 11-point ( $0=$ no pain, $10=$ worst possible pain) Numeric Pain Rating Scale (NPRS). TS scores were calculated by subtracting the first-stimulation pain rating score from the tenth-stimulation pain rating score.

To measure CPM, subjects placed their non-dominant hand into a warm water (46 degrees Celsius) bath. After the hand had been immersed for 30 seconds, a train of 10 consecutive stimuli was applied to the distal aspect of the dominant forearm using \#5.46 von Frey filaments, and subjects were instructed to rate their level of discomfort on the NPRS after the first of 10 stimuli was administered, and again after the 10th stimuli was applied. To quantify CPM, the 10th pain 
report was subtracted from the first, and this number was then subtracted from the score obtained during TS testing. Function was assessed using the Therapeutic Associates Outcome System (TAOS), also known as the Care Connections Outcomes System. The TAOS is a questionnaire designed to address activities specific to 5 anatomic locations, one of which is the temporomandibular joint. It has been shown to demonstrate good test-retest reliability [23,24], as well as concurrent [23], content [23] and criterion [24] validity. The TAOS has been used in one prior study in which subjects were patients with temporomandibular joint pain [25]. Answers are based on a 6-point Likert scale. The author summed scores addressing physical function due to subjects' orofacial pain from 10 questions addressing talking, eating, concentration, headaches and reading, resulting in a possible range of scores from 0 to 50 . Data were coded such that higher numbers indicated greater function.

The author measured pain using the NPRS. Specifically, subjects were instructed to rate the worst pain experienced over the past 24 hours, the least pain over the past 24 hours and the least pain over the past 7 days. The NPRS is used extensively in pain research. Abbott et al., (2014) reported that in subjects with musculoskeletal conditions, the minimal clinically important difference of the NPRS is 1.5 points [26]. To the author's knowledge, psychometric properties of the NPRS have not been studied specifically in subjects with orofacial pain. Several authors have suggested that TS and/or CPM measurements might differ by age $[27,28]$ or gender $[15,29,30,31]$. Therefore, this study evaluated for potential confounding effects by both age and gender in our analyses of the association between TS and CPM, and change in pain and function. All subjects received individualized treatment for their orofacial pain based on diagnostic tests and clinical findings. Treatment consisted of medication, trigger point injections, physical therapy, appliance use, and/or patient education. Subjects were contacted by telephone between 6 and 8 weeks following their initial evaluation, at which time data collection on function and pain were repeated, and data were collected on subjects' perceived change in their condition.

Perceived change over the 6 to 8-week follow-up period were measured using the Global Rating of Change (GROC) scale. The GROC constitutes a single question addressing the patient's perceived change regarding a particular condition over a specified period of time on a 15-point Likert scale, with 0 representing no change. Psychometric properties of the GROC have been addressed in several studies. In relation to lower extremity conditions, the author have concluded that the GROC does not accurately reflect changes in functional levels, but rather is weighted toward the patient's status at follow-up $[32,33]$. In a different study of subjects with shoulder pain, a GROC of 5 or greater was associated with a perceived change in the subject's condition, although it was not associated with changes in physical function [34]. These findings suggest that GROC scores are highly subjective in nature, and might be influenced by location of pain. To the author's knowledge, the GROC has not been studied in patients with orofacial pain. Data were analysed using SAS version 9.3. Since most continuous variables were not normally distributed, Spearman correlation coefficients were calculated. Univariate linear regression models were constructed to estimate the effect of TS and CPM on function, pain and perceived change. Age and gender were then added to the models to estimate their potential confounding effects. Models were evaluated to determine if they met the assumptions of linear regression. In cases in which the assumption of homoscedasticity was violated, heteroscedasticity-consistent estimators were calculated.

\section{Results}

Sixty subjects contributed data at the initial evaluation. Of these, 40 subjects contributed data at follow-up, resulting in a $66.7 \%$ completion rate. The 20 subjects with missing follow-up data were more likely to have lower TAOS scores, but were not different in relation to any of the 3 pain measures or age or gender [see Table 1].

Table 1. Comparison between subjects with complete data at intake and follow-up, and those with missing follow-up data.

\begin{tabular}{|c|c|c|}
\hline $\begin{array}{l}\text { Variable } \\
\text { p-value for the difference } \\
\text { between groups }\end{array}$ & $\begin{array}{l}\text { Subjects with complete } \\
\text { data at intake and follow- } \\
\text { up }(n=40) \\
\text { mean or percentage } \\
\text { (standard deviation) }\end{array}$ & $\begin{array}{l}\text { Subjects with } \\
\text { missing follow-up } \\
\text { data }(\mathbf{n}=\mathbf{2 0}) \\
\text { mean or percentage } \\
\text { (standard deviation) }\end{array}$ \\
\hline $\begin{array}{l}\text { Temporal Summation } \\
p=0.96\end{array}$ & $\begin{array}{c}1.67 \\
(1.86)\end{array}$ & $\begin{array}{c}1.70 \\
(1.89)\end{array}$ \\
\hline $\begin{array}{l}\text { Conditioned Pain } \\
\text { Modulation } \\
\mathrm{p}=0.93\end{array}$ & $\begin{array}{c}0.45 \\
(1.88)\end{array}$ & $\begin{array}{c}0.50 \\
(1.70)\end{array}$ \\
\hline $\begin{array}{l}\text { Therapeutic Associates } \\
\text { Outcome System (TAOS) } \\
\text { score } \\
p=0.01\end{array}$ & $\begin{array}{l}17.47 \\
(4.90)\end{array}$ & $\begin{array}{l}13.80 \\
(5.75)\end{array}$ \\
\hline $\begin{array}{l}\text { 24-hour worst pain } \\
p=0.58\end{array}$ & $\begin{array}{l}5.95 \\
(2.96)\end{array}$ & $\begin{array}{c}6.40 \\
(2.93)\end{array}$ \\
\hline $\begin{array}{l}\text { 7-day worst pain } \\
\mathrm{p}=0.11\end{array}$ & $\begin{array}{c}6.81 \\
(2.95)\end{array}$ & $\begin{array}{c}8.10 \\
(2.67)\end{array}$ \\
\hline $\begin{array}{l}\text { 7-day least pain } \\
p=0.21\end{array}$ & $\begin{array}{c}3.07 \\
(2.84)\end{array}$ & $\begin{array}{c}4.05 \\
(2.68)\end{array}$ \\
\hline $\begin{array}{l}\text { Age } \\
p=0.78\end{array}$ & $\begin{array}{l}45.05 \\
(16.12)\end{array}$ & $\begin{array}{l}46.67 \\
(12.08)\end{array}$ \\
\hline $\begin{array}{l}\text { Gender } \\
\mathrm{p}=1.00\end{array}$ & $75 \%$ female & $75 \%$ female \\
\hline
\end{tabular}

Descriptive statistics for all variables are provided in table 2. Subjects demonstrated statistically significant improvements in all outcome measures over the 6 to 8 -week follow-up period. Specifically, subjects improved in relation to TAOS scores by 1.10 points $(\mathrm{p}=$ $0.03)$, 24-hour worst pain by 2.05 points $(\mathrm{p}<0.01)$, 7-day worst pain by 2.24 points $(\mathrm{p}<0.01)$, and 7 -day least pain by 1.05 points $(\mathrm{p}=0.00)$. The mean GROC score was 2.30 , indicating a perceived improvement of between 'a little bit better' and 'somewhat better'. Change in 24-hour worst pain and 7-day worst pain exceeded the minimal clinically important difference for pain. TS and CPM were both significantly positively correlated with TAOS scores at intake (see Table 3), indicating that greater function was associated with less impaired measurements of CPM measurements, but more impaired TS measurements. None of the 3 intake pain measures were correlated with either TS or CPM measurements. The potential confounding 
influence of age and gender in the association between intake TS and CPM measurements were evaluated, including the change in function and pain, using the criteria that a $10 \%$ change in the effect measure when adding the potential confounder(s) to the baseline model represents meaningful confounding [35]. Analyses suggest that while there is confounding by gender alone or a combination of age and gender in most of the analyses addressing TS, there was no meaningful confounding by either age or gender or both when evaluating the effects of CPM [see Tables 4 and 5]. In relation to change in function or pain over the 6 to 8 week follow up period, there was no evidence of an association between TS and changes in any of the outcome measures irrespective of confounding by age and/or gender [see Table 4]. In univariate analyses, CPM was associated with subjects' reported change in least pain over the past week and with perceived change, but was not associated with any other outcome [see Table 5].

Table 2. Descriptive Statistics of all Dependent and Independent Variables $(n=40)$.

\begin{tabular}{|c|c|}
\hline 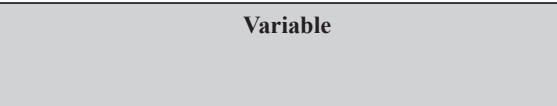 & $\begin{array}{c}\text { Mean or percentage } \\
\text { (standard deviation) } \\
\text { Range }\end{array}$ \\
\hline Temporal Summation & $\begin{array}{l}1.67 \\
(1.86) \\
-1-7\end{array}$ \\
\hline Conditioned Pain Modulation & $\begin{array}{l}0.45 \\
(1.88) \\
-4-5\end{array}$ \\
\hline Age & $\begin{array}{l}45.05 \\
(16.12) \\
22-79\end{array}$ \\
\hline Gender & $75 \%$ female \\
\hline $\begin{array}{l}\text { Therapeutic Associates Outcome System (TAOS) score } \\
\text { at initial visit }\end{array}$ & $\begin{array}{l}17.47 \\
(4.90) \\
6-25\end{array}$ \\
\hline 24-hour worst pain at initial visit & $\begin{array}{l}5.95 \\
(2.96) \\
0-10\end{array}$ \\
\hline 7-day worst pain at initial visit & $\begin{array}{c}6.81 \\
(2.95) \\
0-10\end{array}$ \\
\hline 7-day least pain at initial visit & $\begin{array}{l}3.07 \\
(2.84) \\
0-10\end{array}$ \\
\hline $\begin{array}{l}\text { Therapeutic Associates Outcome System (TAOS) score } \\
\text { at } 6 \text { to } 8 \text { weeks follow-up }\end{array}$ & $\begin{array}{l}18.57 \\
(4.78) \\
9-25\end{array}$ \\
\hline 24-hour worst pain at 6 to 8 weeks follow-up & $\begin{array}{l}3.90 \\
(3.14) \\
0-10\end{array}$ \\
\hline 7-day worst pain at 6 to 8 weeks follow-up & $\begin{array}{c}4.57 \\
(2.96) \\
0-10\end{array}$ \\
\hline 7-day least pain at 6 to 8 weeks follow-up & $\begin{array}{c}2.02 \\
(2.17) \\
0-8\end{array}$ \\
\hline Global Rating of Change & $\begin{array}{l}2.30 \\
(2.48) \\
-3-7\end{array}$ \\
\hline
\end{tabular}

Table 3. Spearman correlation coefficients for the correlation between measures of temporal summation and conditioned pain modulation; and function, pain, age and gender at initial evaluation.

\begin{tabular}{|l|c|c|}
\hline & $\begin{array}{c}\text { Temporal } \\
\text { Summation } \\
\mathbf{r}_{\mathbf{s}} \\
\text { p-value }\end{array}$ & $\begin{array}{c}\text { Conditioned Pain } \\
\text { Modulation } \\
\mathbf{r}_{\mathbf{s}} \\
\text { p-value }\end{array}$ \\
\hline Therapeutic Associates Outcome System & 4.69 & 0.43 \\
(TAOS) score & 0.00 & 0.01 \\
\hline 24-hour worst pain & -0.01 & 0.07 \\
& 0.97 & 0.65 \\
\hline 7-day worst pain & 0.05 & 0.04 \\
& 0.77 & 0.82 \\
\hline 7-day least pain & 0.11 & 0.18 \\
& 0.49 & 0.26 \\
\hline Age & -0.19 & -0.20 \\
& 0.24 & 0.23 \\
\hline Gender (female vs. male) & 0.06 & 0.09 \\
& 0.70 & 0.58 \\
\hline
\end{tabular}

\section{Discussion}

The study's first aim was to determine if TS and CPM tests are correlated with physical function and pain measurements during the initial visit for treatment of their orofacial pain. As expected, study results demonstrated a significant correlation between higher levels of function at intake and blunted pain response from concurrent noxious stimuli during CPM testing. In contrast, higher levels of function at intake were significantly correlated with heightened pain response from consecutive noxious stimulation during TS testing. Equally surprising is the absence of a statistically significant correlation between the three self-reported pain scores at intake, and TS and CPM measurements, since both TS and CPM are believed to be measures of an elevated response to pain. These latter findings call into question the validity of either TS or CPM testing to identify patients with orofacial pain whose pain is at least partially explained by heightened centrally and/or peripherally-mediated pain processes.

To the author's knowledge, the correlation between self-reported baseline pain intensity measures and psychophysical quantitative sensory tests using TS and CPM have not been closely studied among subjects with orofacial pain. However, these tests have been used to compare pain processing mechanisms between patients with orofacial pain and pain-free controls in 3 separate studies. Contrary to this study's results, Kothari et al. (2015) found heightened TS to pinprick sensation among subjects with orofacial pain compared with healthy controls [10]. However, no differences between both groups were reported in CPM test outcomes when pinprick test stimulus was concurrently applied with a cold conditioning stimulus [10]. This was the case irrespective of whether the test stimulus was applied to the site of pain or at a distal site. Oono, et al., (2014) paired a pinprick test stimulus with pressure as the conditioned stimulus and found that CPM test results were more impaired in subjects with orofacial pain compared with pain free controls when the painful stimulation was applied at the site of pain but not over a distal, pain free site [14]. In this study, significant correlation were found between CPM test outcomes and one of three pain outcomes when test stimulus was applied at a site distal to pain. 
Carla S. Enriquez (2019) Is Temporal Summation or Conditioned Pain Modulation Associated with Pain and Functional Outcomes in Patients with Orofacial Pain?

Table 4. Association between temporal summation and change in function, pain and global rating of change.

\begin{tabular}{|c|c|c|c|c|}
\hline Outcome Variable & $\begin{array}{l}\text { Baseline model for the association } \\
\text { between temporal summation } \\
\text { and outcome } \\
\text { beta } \\
\text { p-value } \\
\text { model } \mathrm{r}^{2}\end{array}$ & $\begin{array}{c}\text { Baseline model + age } \\
\text { beta } \\
\text { p-value } \\
\text { model } \mathrm{r}^{2}\end{array}$ & $\begin{array}{c}\text { Baseline model }+ \text { gender } \\
\text { beta } \\
\text { p-value } \\
\text { model } \mathrm{r}^{2}\end{array}$ & $\begin{array}{c}\text { Baseline model }+ \text { age }+ \text { gender } \\
\text { beta } \\
\text { p-value } \\
\text { model } \mathrm{r}^{2}\end{array}$ \\
\hline $\begin{array}{l}\text { Change in Therapeutic } \\
\text { Associates Outcome System } \\
\text { (TAOS) score }\end{array}$ & $\begin{array}{l}-0.02 \\
0.95 \\
0.65\end{array}$ & $\begin{array}{l}0.02 \\
0.95 \\
0.65\end{array}$ & $\begin{array}{l}0.00 \\
0.99 \\
0.65\end{array}$ & $\begin{array}{l}0.03 \\
0.91 \\
0.65\end{array}$ \\
\hline $\begin{array}{l}\text { Change in 24-hour worse } \\
\text { pain }\end{array}$ & $\begin{array}{c}-0.10 \\
0.64 \\
0.42\end{array}$ & $\begin{array}{c}-0.06 \\
0.80 \\
0.43\end{array}$ & $\begin{array}{l}-0.18 \\
0.41 \\
0.46\end{array}$ & $\begin{array}{c}-0.13 \\
0.58 \\
0.47\end{array}$ \\
\hline Change in 7-day worse pain & $\begin{array}{l}-0.19 \\
0.43 \\
0.19\end{array}$ & $\begin{array}{l}-0.12 \\
0.65 \\
0.21\end{array}$ & $\begin{array}{l}-0.28 \\
0.25 \\
0.27\end{array}$ & $\begin{array}{l}-0.20 \\
0.42 \\
0.30\end{array}$ \\
\hline Change in 7 - day least pain & $\begin{array}{c}-0.16 \\
0.12 \\
0.54\end{array}$ & $\begin{array}{r}-0.20 \\
0.17 \\
0.55\end{array}$ & $\begin{array}{l}-0.20 \\
0.15 \\
0.56\end{array}$ & $\begin{array}{l}-0.22 \\
0.13 \\
0.56\end{array}$ \\
\hline Global Rating of Change & $\begin{array}{l}0.32 \\
0.14 \\
0.06\end{array}$ & $\begin{array}{l}0.33 \\
0.16 \\
0.06\end{array}$ & $\begin{array}{l}0.38 \\
0.09 \\
0.09\end{array}$ & $\begin{array}{l}0.38 \\
0.11 \\
0.09\end{array}$ \\
\hline
\end{tabular}

Table 5. Association between conditioned pain modulation and change in function, pain and global rating of change.

\begin{tabular}{|c|c|c|c|c|}
\hline Outcome Variable & $\begin{array}{l}\text { Baseline model for the association } \\
\text { between conditioned pain modulation } \\
\text { and outcome } \\
\text { beta } \\
\text { p-value } \\
\text { model } \mathrm{r}^{2}\end{array}$ & $\begin{array}{c}\text { Baseline model plus age } \\
\text { beta } \\
\text { p-value } \\
\text { model } \mathrm{r}^{2}\end{array}$ & $\begin{array}{c}\text { Baseline model plus gender } \\
\text { beta } \\
\text { p-value } \\
\text { model } \mathrm{r}^{2}\end{array}$ & $\begin{array}{c}\text { Baseline model plus age and } \\
\text { gender } \\
\text { beta } \\
\text { p-value } \\
\text { model } \mathrm{r}^{2}\end{array}$ \\
\hline $\begin{array}{l}\text { Change in Therapeutic } \\
\text { Associates Outcome System } \\
\text { (TAOS) score }\end{array}$ & $\begin{array}{l}0.07 \\
0.77 \\
0.65\end{array}$ & $\begin{array}{l}0.08 \\
0.76 \\
0.65\end{array}$ & $\begin{array}{l}0.08 \\
0.77 \\
0.65\end{array}$ & $\begin{array}{l}0.08 \\
0.76 \\
0.65\end{array}$ \\
\hline Change in 24 - hour worse pain & $\begin{array}{l}-0.35 \\
0.09 \\
0.46\end{array}$ & $\begin{array}{l}-0.34 \\
0.10 \\
0.47\end{array}$ & $\begin{array}{l}-0.34 \\
0.10 \\
0.49\end{array}$ & $\begin{array}{c}-0.33 \\
0.11 \\
0.51\end{array}$ \\
\hline Change in 7-day worse pain & $\begin{array}{l}-0.30 \\
0.21 \\
0.21\end{array}$ & $\begin{array}{l}-0.28 \\
0.23 \\
0.24\end{array}$ & $\begin{array}{l}-0.29 \\
0.21 \\
0.27\end{array}$ & $\begin{array}{l}-0.27 \\
0.23 \\
0.31\end{array}$ \\
\hline Change in 7 - day least pain & $\begin{array}{c}-0.39 \\
0.00 \\
0.64\end{array}$ & $\begin{array}{c}-0.39 \\
0.00 \\
0.64\end{array}$ & $\begin{array}{l}-0.39 \\
0.00 \\
0.65\end{array}$ & $\begin{array}{l}-0.39 \\
0.00 \\
0.65\end{array}$ \\
\hline Global Rating of Change & $\begin{array}{l}0.41 \\
0.05 \\
0.10\end{array}$ & $\begin{array}{l}0.41 \\
0.05 \\
0.10\end{array}$ & $\begin{array}{l}0.40 \\
0.06 \\
0.11\end{array}$ & $\begin{array}{l}0.40 \\
0.06 \\
0.12\end{array}$ \\
\hline
\end{tabular}

Differences in reported study outcomes are likely due in part to differences in TS and CPM testing protocol and instrumentation used across studies. There is currently no strong evidence supporting the most effective method for conducting TS or CPM testing in patients with orofacial pain, however the method chosen to test TS did not demonstrate construct validity in relation to its correlations with function or pain, whereas the method we chose to test CPM demonstrated somewhat more promising results. The second aim was to determine if TS and CPM tests, performed on subjects with orofacial pain during their initial visit for treatment of their orofacial pain, are associated with changes in physical function and pain at 6 to 8-weeks follow-up. In relation to TS testing, there were no significant differences between intake TS measurements, and any of the outcome measures tested, suggesting that the method of TS testing used in this study may not be a useful tool for predicting change in function or pain in patients with orofacial pain.

Statistically significant association between CPM test scores were found; and change in least pain reported over the 7-day period prior to follow up, including perceived change over the 6 to 8 -week follow-up period. Specifically, a more heightened response to painful stimuli with CPM testing was associated with less pain reduction and perceived improvement at follow-up. There were no significant 
differences between intake CPM scores and changes in function or in changes in 24-hour worst or 7-day worst pain. The finding that CPM measures were associated with only two of five clinically important outcomes suggests that the instrumentation or measurement strategies administered as part of this study are not sensitive enough to effectively discriminate between different levels of perceived pain and function, or that there simply is not an association between CPM scores and changes in function and most measurements of pain.

This study had several limitations, all of which relate to the study design, where a sample of convenience with orofacial pain were recruited, and therefore cannot determine how representative this sample is of the population of orofacial pain patients. Additionally, $33 \%$ of subjects who contributed data at initial evaluation did not contribute follow-up data. These subjects who were lost to follow-up were more likely to have lower physical function levels, indicating a possible bias affecting study results. Finally, data on potential confounders other than age and gender, such as pain duration were not collected, which could influence study outcomes.

\section{Conclusion}

Study results suggest that TS testing, as implemented in this study is not useful for identifying patients with orofacial pain who have heightened pain sensitivity; or who are more likely to have poorer function and pain outcomes, or less perceived improvement following treatment for their orofacial pain. Similarly, CPM testing did not demonstrate utility in identifying orofacial pain patients with impaired pain processing at the initial examination, although it demonstrated some promise in identifying subjects who are likely to have worse pain outcomes and lower levels of perceived improvement. Nevertheless, additional research is warranted before considering the use of CPM testing as a measurement tool in the clinical or research setting.

\section{Funding Details}

This work was supported by the University of Medicine and Dentistry of New Jersey - School of Health- Related Professions PreDoctoral Fellowship Grant.

\section{Acknowledgement}

The author wishes to recognize the following individuals for their contributions: Susan Edmond, PT, DSc, OCS, School of Health Professions, Rutgers University Newark, NJ, USA; Gary M. Heir, DMD and Cibele Nasri-Heir, DDS, MSD, School of Dental Medicine, Rutgers University, Newark, NJ, USA.

\section{References}

1. Merskey H, Bogduk N (1994) Part III: Pain terms, a current list with definitions and notes on usage. Classification of chronic pain, 2nd ed. International Association in the Study of Pain Task Force on Taxonomy. International Association in the Study of Pain. Available from: http://www.iasp-pain.org.

2. Horst OV, Cunha-Cruz J, Zhou L, Manning W, Mancl L, et al. (2015) Prevalence of pain in the orofacial regions in patients visiting general dentists in the northwest practice-based research collaborative in evidence-based dentistry research network. J Am Dent Assoc 146: 721-728. [crossref]

3. de Siqueira SR, Teixeira MJ, de Siqueira JT (2013) Orofacial pain and sensory characteristics of chronic patients compared with controls. Oral Surg Oral Med Oral Pathol Oral Radiol 115: 37-45. [crossref]
4. Greenspan JD, Slade GD, Bair E, Dubner R, Fillingim RB, et al. (2013) Pain sensitivity and autonomic factors associated with development of TMD: the OPPERA prospective cohort study. J Pain 14: 63-74. [crossref]

5. Fernandez-de-las-Penas C, Galan-del-Rio F, Fernandez-Carnero J, Pesquera J, Arendt-Nielsen L, et al. (2009) Bilateral widespread mechanical pain sensitivity in women with myofascial temporomandibular disorder: evidence of impairment in central nociceptive processing. J Pain 10: 1170-1178. [crossref]

6. Greenspan JD, Slade GD, Bair E, Dubner R, Fillingim RB, et al. (2011) Pain sensitivity risk factors for chronic TMD: Descriptive data and empirically identified domains from the OPPERA case control study. Journal of Pain 12: 61-74. [crossref]

7. Gustin SM, Peck CC, Wilcox SL, Nash PG, Murray GM, et al. (2011) Different pain, different brain: thalamic anatomy in neuropathic and non-neuropathic chronic pain syndromes. J Neurosci 31: 5956-5964. [crossref]

8. Staud R (2012) Abnormal endogenous pain modulation is a shared characteristic of many chronic pain conditions. Expert Rev Neurother 12: 577-585. [crossref]

9. Vierck CJ, Wong F, King CD, Mauderli AP, Schmidt S, et al. (2014) Characteristics of sensitization associated with chronic pain conditions. Clin J Pain 30: 119-128. [crossref]

10. Kothari SF, Baad-Hansen L, Oono Y, Svensson P (2015) Somatosensory assessment and conditioned pain modulation in temporomandibular disorders pain patients. Pain 156: 2545-2555. [crossref]

11. Maixner W, Fillingim R, Sigurdsson A, Kincaid S, Silva S (1998) Sensitivity of patients with painful temporomandibular disorders to experimentally evoked pain: evidence for altered temporal summation of pain. Pain 76: 71-81. [crossref]

12. Staud R, Robinson ME, Price DD (2007) Temporal summation of second pain and its maintenance are useful for characterizing widespread central sensitization of fibromyalgia patients. J Pain 8: 893-901. [crossref]

13. Pavlaković G, Petzke F (2010) The role of quantitative sensory testing in the evaluation of musculoskeletal pain conditions. Curr Rheumatol Rep 12: 455-461. [crossref]

14. Oono Y, Wang K, Baad-Hansen L (2014) Conditioned pain modulation in temporomandibular disorders (TMD) pain patients. Experimental Brain Research 232: 3111-3119. [crossref]

15. Sarlani E, Garrett PH, Grace EG, Greenspan JD (2007) Temporal summation of pain characterizes women but not men with temporomandibular disorders. Journal of Orofacial Pain 21: 309-317. [crossref]

16. Nie H, Graven-Nielsen T, Arendt-Nielsen L (2009) Spatial and temporal summation of pain evoked by mechanical pressure stimulation. European Journal of Pain 13: 592-599. [crossref]

17. Koltyn KF, Knauf MT, Brellenthin AG (2013) Temporal summation of heat pain modulated by isometric exercise. European Journal of Pain 17: 1005-1011. [crossref]

18. Kong JT, Johnson KA, Balise RR, Mackey S (2013) Test-retest reliability of thermal temporal summation using an individualized protocol. The Journal of Pain 14: 79-88. [crossref]

19. Cathcart S, Winefield AH, Rolan, P, Lushington K (2009) Reliability of temporal summation and diffuse noxious inhibitory control. Pain Research \& Management 14: 433-438. [crossref]

20. Lewis GN, Heales L, Rice DA, Rome K, McNair PJ (2012) Reliability of the conditioned pain modulation paradigm to assess endogenous inhibitory pain pathways. Pain Research \& Management: The Journal Of The Canadian Pain Society 17: 98-102. [crossref]

21. Sato H, Saisu H, Muraoka W, Nakagawa T, Svensson P, et al. (2012) Lack of temporal summation but distinct aftersensations to thermal stimulation in patients with combined tension-type headache and myofascial temporomandibular disorder. Journal of orofacial pain 26: 288-295. [crossref]

22. Moont R, Pud D, Sprecher E, Sharvit G, Yarnitsky D (2010) 'Pain inhibits pain' mechanisms: Is pain modulation simply due to distraction? Pain 150: 113-120. [crossref]

23. Schunk C, Rutt R (1998) TAOS functional index orthopaedic rehabilitation outcomes tool. Journal of Rehabilitation Outcomes Measurement 2: 55-61.

24. Hoekstra CJ, Deppeler DA, Rutt RA (2014) Criterion validity, reliability and clinical responsiveness of the care connections functional index. Physiotherapy Theory and Practice 30: 429-437.

25. Badke MB, Dussault L, Boissonnault W (2007) Influence of symptom longevity on outcomes following a customized rehabilitation program for painful temporomandibular disorders. Physiotherapy Canada. 59: 10-21.

26. Abbott JH, Schmitt J (2014) Minimum important differences for the patient-specific functional scale, 4 region-specific outcome measures, and the numeric pain rating scale. J Orthop Sports Phys Ther 44: 560-564. [crossref]

27. Lautenbacher S, Kunz M, Strate P, Nielsen J, Arendt-Nielsen L (2005) Age effects on pain thresholds, temporal summation and spatial summation of heat and pressure pain. Pain 115: 410-418. [crossref] 
Carla S. Enriquez (2019) Is Temporal Summation or Conditioned Pain Modulation Associated with Pain and Functional Outcomes in Patients with Orofacial Pain?

28. Cole LJ, Farrell MJ, Gibson SJ, Egan GF (2010) Age-related differences in pain sensitivity and regional brain activity evoked by noxious pressure. Neurobiology of Aging 31: 494-503. [crossref]

29. France CR, Suchowiecki S (1999) A comparison of diffuse noxious inhibitory controls in men and women. Pain 81: 77-84. [crossref]

30. Shinal RM, Fillingim RB (2007) Overview of orofacial pain: epidemiology and gender differences in orofacial pain. Dent Clin North Am 51: 1-18, [crossref]

31. Martel MO, Wasan AD, Edwards RR (2013) Sex differences in the stability of conditioned pain modulation (CPM) among patients with chronic pain. Pain Med 14: 1757-1768. [crossref]

32. Schmitt JS, Abbott JH (2014) Patient global ratings of change did not adequately reflect change over time: a clinical cohort study. Physical Therapy 94: 534-542. [crossref]
33. Schmitt JS; Abbott JH (2015) Global ratings of change do not accurately reflect functional change over time in clinical practice. Journal of Orthopaedic \& Sports Physical Therapy 45: 106-111. [crossref]

34. Garrison JC, Shanley E, Thigpen C, Hegedus E, Cook C (2011) Between-session changes predict overall perception of improvement but not functional improvement in patients with shoulder impingement syndrome seen for physical therapy: An observational study. Physiotherapy Theory and Practice 27: 137-145. [crossref]

35. Rothman KJ (1986) Modern Epidemiology. Little, Brown and Company, Boston/ Toronto, USA.

\section{Citation:}

Enriquez CS (2019) Is Temporal Summation or Conditioned Pain Modulation Associated with Pain and Functional Outcomes in Patients with Orofacial Pain?. Integr J Orthop Traumatol Volume 2 (1): 1-7. 